\title{
Comparative Studies on Some Physicochemical Properties of Baobab, Vegetable, Peanut and Palm Oils
}

\author{
${ }^{* 1}$ U.A. Birnin-Yauri and ${ }^{2}$ S. Garba \\ ${ }^{1}$ Department of Pure and Applied Chemistry, Usmanu Danfodiyo University, Sokoto Nigeria \\ ${ }^{2}$ Department of Chemistry, Nigerian Defence Academy, Kaduna Nigeria \\ [*Corresponding Author: uabyauri@yahoo.com; Tel.: +234(0)*38099456]
}

\begin{abstract}
Industrial and nutritional processes have increased the demands for oil and this in turn has led to the search for oils from different types of seeds. It is in this vein that baobab seed oil was extracted, analyzed and some of it physicochemical properties compared with those of vegetable, peanut and palm oils. The percentage yield, iodine value, acid value, peroxide value, moisture, free fatty acids and gossypol content of the oils were determined. The results show that baobab seed oil has quality comparable with those of commercial oil and it has great nutritional and industrial potentials. It is therefore recommended that more research be undertaken for this abundant source of natural nutritious oil.

Keywords: Physicochemical properties, vegetable Oils, Baobab.
\end{abstract}

\section{INTRODUCTION}

Fat and oils are nutritionally important because they form one of the three major classes of food. Oils are used in a variety of ways. They are used for food texturing, baking, and frying and also used industrially, in the manufacture of soap, detergent, cosmetics and oil paints. In plants, oil is deposited in the seeds mostly in the endosperm along with carbohydrates where they jointly nourish the embryo (Oyeyiola, 1993). It is also found in some plants mesocarp e.g. in palm fruits. In animals, oil is found in various parts of the body e.g. liver (Oyeyiola, 1993). Nutritional and industrial processes have increased the demands for oils and this in turn has led to the search for oils from different types of seeds.

The leaves and fruits of baobab plants are eaten as food in Northern Nigeria. The seeds are in most cases discarded; and no attention has been paid to its nutritive and other uses. Baobab seeds were obtained from the baobab tree genus: Adansonia digitata, family: Bombacaceae. The tree bears long and large fruit, which has sweet taste when ripe. They are sometimes called monkey bread. The tree is native to the tropics but cultivated in other non-tropical regions of the world (Edward, 1974).
The research aimed at the quantification of the oil content of the baobab seeds and its physicochemical properties and comparing these properties with those of commonly used vegetable oils. The comparison may ascertain the suitability or otherwise of the baobab seed oil for human consumption and industrial applications.

\section{MATERIALS AND METHOD Sampling}

A. digitata fruits were collected from YelwaYauri, Kebbi State, Nigeria. The fruits were sundried and broken to obtain the seeds, which were subsequently sun-dried again and further broken to obtain the kernels. Peanut oil and vegetable oil were obtained from Zamfara Oil Mill Gusau, while the palm oil was obtained from a market in Yelawa-Yauri.

\section{Oil extraction}

The baobab oil was extracted from $100 \mathrm{~g}$ powdered kernel with $250 \mathrm{ml}$ cyclohexene using Soxhlet extractor for $3 \mathrm{~h}$. The cyclohexene was evaporated under vacuum leaving behind light brown oil with an aroma like that of palm oil.

\section{Determination of Saponification Value}

Exactly $1.0 \mathrm{~g}$ of the oil sample was dissolved in $3 \mathrm{ml}$ of chloroform in a $50 \mathrm{ml}$ conical flask. Then $25 \mathrm{ml}$ of $1 \%$ phenolphthalein was added and the 
solution was titrated to a colorless end point with $0.5 \mathrm{M} \mathrm{HCl}$. A blank titration was run in all respect (Hildith and Williams, 1964).

\section{Determination of Iodine Value}

To $5 \mathrm{ml}$ of the chloroform solution of the oil, $5 \mathrm{ml}$ of Dam's reagent was added. The mixture was kept in fume cupboard for $10 \mathrm{~min}$. and $5 \mathrm{ml}$ of $10 \% \mathrm{KI}$ and $20 \mathrm{ml}$ of water were added. The mixture was thoroughly mixed and titrated to a colourless end point with $0.025 \mathrm{M} \mathrm{Na} \mathrm{Na}_{2} \mathrm{~S}_{2} \mathrm{O}_{3}$ solution. The control was treated in a similar way (Bailey, 1951).

\section{Determination of Moisture Content}

Three crucibles were weighed and into each $10 \mathrm{~g}$ of the oil sample were added. The samples were dried to constant weights in an oven at $105^{\circ} \mathrm{C}$, cooled in desiccators and weighed. The procedure was repeated thrice for each sample and the average value was determined (Edcey, 1957).

\section{Determination of Peroxide Value}

Exactly $1.0 \mathrm{~g}$ of $\mathrm{KI}$ and $20 \mathrm{ml}$ of solvent mixture (glacial acetic acid: chloroform, 2:1 v/v) were added to $1.0 \mathrm{~g}$ of the oil sample and the mixture was boiled for one minute. The hot solution was poured into a flask containing $20 \mathrm{ml}$ of $5 \% \mathrm{KIO}_{3}$ solution. Few drops of starch solution were added to the mixture and the latter was titrated with 0.025 $\mathrm{M} \mathrm{Na}_{2} \mathrm{~S}_{2} \mathrm{O}_{3}$ solution (Lummer, 1978).

\section{Determination of Acid Value}

Exactly $2.0 \mathrm{~g} \mathrm{Ba}(\mathrm{OH})_{2}$ was added to $0.1 \mathrm{M} \mathrm{KOH}$ solution and left for $5 \mathrm{~min}$. The solution was cooled, filtered and stored in a plastic bottle. The resulting solution was standardized using $0.10 \mathrm{M}$ $\mathrm{KHC}_{8} \mathrm{H}_{4} \mathrm{O}_{4}$ (potassium hydrogen phthalate) solution. The solvent mixture was neutralized with standard $0.1 \mathrm{M} \mathrm{KOH}$ solution until persistent faint pink colour appeared. Then $1.25 \mathrm{~g}$ of the oil was transferred into a $250 \mathrm{ml}$ conical flask and $125 \mathrm{ml}$ of the solvent mixture was added to the sample. This was dissolved by agitation and warming on a steam bath. At this point the pink colour disappeared and a clear solution was obtained. The solution was titrated against the $0.1 \mathrm{M} \mathrm{KOH}$ solution. The end point was obtained by the restoration of the pink colour. The procedure was repeated thrice and the average end point obtained (Edcey, 1954).

\section{Determination of the Free Fatty Acids of the Oil Samples}

To $20 \mathrm{ml}$ of ethanol : diethyl ether $(1: 1 \mathrm{v} / \mathrm{v})$ mixture, $2 \mathrm{ml}$ of $1 \%$ phenolphthalein solution was added and the mixture was neutralised using $0.10 \mathrm{M} \mathrm{NaOH}$ solution. Then $5 \mathrm{~g}$ of each oil sample was added to the neutralized mixture and titrate against $0.10 \mathrm{M} \mathrm{NaOH}$ solution with constant shaking until a pink colour developed and persisted for 15 minutes. The titre values were used to obtain the free fatty acid value (Admusa, 1984).

\section{Extraction and Determination of the Oil Gossypols Content}

Five grammes $(5 \mathrm{~g})$ each of the oil samples were placed into a $100 \mathrm{ml}$ Erlenmeyer flask to which $100 \mathrm{mg}$ of anhydrous sodium sulphate and $5 \mathrm{ml}$ of petroleum ether $\left(40-60^{\circ} \mathrm{C}\right)$ were added. The content was mixed thoroughly and was centrifuged for $10 \mathrm{~min}$. The resulting supernatant was decanted into a $250 \mathrm{ml}$ beaker and the extraction was repeated twice. $10 \mathrm{ml}$ of diethyl ether was added to the residue while shaking. The mixture was centrifuged and the resulting supernatant was decanted into a receiving $250 \mathrm{ml}$ beaker. The extraction was repeated twice and the extracts were evaporated to dryness in fume cupboard. The residue was dissolved in absolute ethanol and transferred into a $25 \mathrm{ml}$ volumetric flask and made up to the mark (Abalaka et al 1978; Bailey, 1999).

\section{Preparation of Standard Curve}

The standard curve was prepared from a standard gossypol solution containing $90 \%$ pure dried gossypol standard. 20\% (w/v) solution of gossypol/ absolute ethanol was prepared. Ferric chloride-bipyridyl reagent was prepared by dissolving $0.5 \mathrm{~g}$ of ferric chloride with $0.5 \mathrm{~g}$ of 2 , 2 - bipyridyl reagent in $100 \mathrm{ml}$ absolute ethanol. $1 \mathrm{ml}$ of bipyridyl reagent was added to each aliquot of gossypol standard solution in ethanol, the mixture was left in the dark for 15 minutes for colour development and the absorbance was read at 510nm (Abalaka et.al., 1978). 


\section{Determination of the Gossypol Content}

To $2 \mathrm{ml}$ of the ethanol extract, $1 \mathrm{ml}$ of ferric chloride- bipyridyl reagent was added, and made to volume in a $25 \mathrm{ml}$ volumetric flask and stored in the dark for 15 minutes. Absorbance reading of the samples was then taken in triplicate at 510nm using Beckman DB Spectrophotometer in $10 \mathrm{~mm}$ glass cuvette against a reagent blank. The gossypol content of each sample was then extrapolated from a standard curve (Abalaka et at., 1978).

\section{RESULTS AND DISCUSSION}

Baobab seed has an appreciable amount of oil $(22.50 \%)$. This shows that if commercially exploited, it could serve as one of the major additional sources of oil. Baobab seed oil has been found to have the highest iodine and saponification values (Table 1), indicating that it is the most unsaturated of the four oil samples studied. Thus, it may be found in liquid form at room temperature (Hildith and Williams, 1964; Muhammad, et al., 2006). Palm oil has the lowest iodine and saponification values implying that is the most saturated. Since saponification value is inversely proportional to the molecular weight of the fatty acid present in oil, it can be concluded that Baobab seed oil contains glycerides with the highest molecular weights (Bailey, 1951; Muhammad, et al., 2006).

All the oils can be used in the manufacture of soap (Table 1). However, baobab seed oil has the lowest value of acid acid (as oleic acid) while palm oil has the highest $(20 \%)$. This makes baobab seed oil least suitable and palm oil the most suitable ingredient for soap manufacture (Liman, 1998). The acids values of palm oil, peanut oil and vegetable oil are far below the toxic level. Hence, they are better oils for paint and soap manufacture than baobab seed oil (Abalaka, et al., 1978).

The low free fatty acid in the case of Baobab seed oil (0.24) and vegetable oil (0.32), though a disadvantage in the paint and soap industry may be an advantage over the other samples in terms of human consumption (Mitchel, 1962 and Musa, 1992).
The rate of non-enzymatic rancidity of oil depends on the extent of its exposure and its susceptibility to oxidation. Hence, the higher peroxide values of the palm oil (16.08) and peanut oil (5.12) suggest that they would be more susceptible to rancidity than the baobab seed oil (10.15) and the vegetable oil (8.50) (Edcey, 1954; Babura and Obuzor, 2005; Muhammad, et al., 2006). It is therefore necessary to develop improved methods of storing these oils. Addition of anti oxidant such as butylhydroxy anisole reduces such susceptibility to rancidity (Admusa and Chandravanshi, 1984).

Table 1: Physicochemical Properties of the Oils.

\begin{tabular}{lllll}
\hline Parameter & Baobab & TVO & Peanut & Palm \\
\hline $\mathrm{IV}\left(\mathrm{gI}_{2} / \mathrm{g}\right)$ & 82.58 & 81.30 & 65.52 & 60.90 \\
$\mathrm{AV}()$ & 3.14 & 7.50 & 15.00 & 20.00 \\
$\mathrm{SV}(\mathrm{mgKOH} / \mathrm{g})$ & 186 & 186 & 165 & 140 \\
$\mathrm{PV}()$ & 10.15 & 8.50 & 5.12 & 16.08 \\
$\mathrm{MC}(\%)$ & 0.20 & 0.25 & 1.02 & 0.20 \\
$\mathrm{FA}(\%)$ & 0.24 & 0.32 & 0.92 & 0.53 \\
$\mathrm{GC}(\mu \mathrm{g} / \mathrm{g})$ & 10.00 & nd & 10.00 & nd \\
\hline
\end{tabular}

IV=Iodine Value;

$\mathrm{AV}=$ Acid Value;

$\mathrm{SV}=$ Saponification Value;

FA=Fatty Acid;

PV Peroxide Value;

TVO=Turkey Vegetable oil;

$\mathrm{MC}=$ Moisture Content;

$\mathrm{GC}=$ Gossypol Content

Palm oil and peanut oil have moisture content of 0.2 and 1.02 respectively, while baobab seed oil and vegetable oil 0.2 and $0.25 \%$ (Table 1).

The oils show a similar trend for the free fatty acid content (Table 1), implying that the higher the value of the moisture content of the oil, the greater the value used for food texturing, baking, and frying and industrially in the manufacture of soaps, detergents, cosmetics and oil paints.

Gossypol is regarded as a major constrain in the consumption of oil by human beings. It is known as an important inhibitor of sperm formation that the entire region of Jiangsu in China produces no children, while they were using the gossypol-containing (cotton-seedy oil. 
This oil is recently under consideration for use as potential reversible male contraceptive (Yu et al., 1998; Waites et al., 1998).

The results of this investigation on gossypol content showed that Baobab seed oil contains $0.001 \%$ (Table 1) which is far below the safe margin (0.01\%w/v) (Lyman, et al., 1986). The gossypol detected from peanut oil $(0.001 \%)$ might be connected with the practice of mixing peanut seed with cotton seed for oil processing as cotton seed are known to be a major source of gossypol (Admasu and Chandravanshi, 1984; Yu et al., 1998).

\section{CONCLUSION AND RECOMMENDATION}

The results show that Baobab seed oil is not inferior to other edible oils used for cooking. It is safe for human consumption and recommended that more research should be carried out to explore its viability for both nutritional and industrial use.

\section{REFERENCES}

Abalaka, J. A., Ahamed, D.A., Adedoja, F.A. (1987). Assessment of Biochemical, Nutritional and Industrial qualities of Rubber seed oil; Nig. J. Biotechnol. 3: 5458.

Admasu, A. and Chandravanshi, B. S. (1984) Spectrophotometric Determination of Total Gossypol in Cotton Seed and Cotton Seed Meals. J. Analyt. Chem. 56: 30-38.

Babura, F.D. and Obuzor, G.U. (2005). Analysis of Essential Oils from Citrus Lantus; Decrodes Edulis and Irvingia Int. J. Sci. Technol. 4(1\&2): 44-47.

Bailey, A.E. (1951). Industrial Oil and Fat Products, $\quad 2^{\text {nd }}$ edition, Interscience publishers, New York, pp. 58-109.

Edcey, E.W. (1954). Vegetable Fats and Oils. American Chemical Society Monograph Series, Reinhold Publication Company, New York pp 582-584.
Edward, H. (1974). New Age Encyclopedia Lexicon Publication New York, 2; 377.

Edward, H. (1974). New Encyclopedia lexicon Publication New York, 2:377

Hildith, T.P. and Williams, P.N. (1964). The Chemical Constituents of Natural Fats, $15^{\text {th }}$ edition, Chapman Publishers London, pp. 50-56.

Liman, M.N. (1998). Extraction and Analysis of Fat/Oil from the seed of Adansonia digitata (Baobab tree) A B.Sc. research project report submitted to the Department of Pure and Applied Chemistry, Usmanu Danfodiyo University Sokoto (Unpublished), pp. 10-22.

Mitchel, H.H. (1962). Comparative Nutritional Analysis of Man and Domestic Animals, Academic Press, New York, pp. 80-83.

Musa, D.E. (1992). The Locust Bean fruit as a Potential Source of Chemical Raw Materials. A paper Presented at the Preliminary Session on the occasions of the National Seminar on Industrial and Social Aspect of Chemistry (ISAC' 92), Collage of Arts, Science and Remedial Studies, Kano. $25^{\text {th }}-27^{\text {th }}$ May, 1992.

Muhammad, C., Ladan, M.J. and Wasagu, R.U. S. (2006). Comparative Analysis of Vegetable oils in Bodinga, Sokoto State, Nigeria. Bio. Environ. J. Trop. 3(1): 113116.

Oyeyiola, J.A. (1993). Nigerian Foods and Feeding Stuff IUP Ibadan: pp 50-52

Robert, M. (1978). Encyclopaedia Britannica Macropaedia, Helen Hemingway Benton Publisher Chicago 15: 628.

Wartes, G.M.H, Wang, C. and Griffin, P.D. (1998). Gossypol: Reason for its Failure to be accepted as a safe reversible male ant- fertility drug. Int. J. Androl; 21; 8-12.

$\mathrm{Yu}$, Z.H. and Chan, H.C. (1998). Gossypol as male ant-fertility, Why studies should have continued. Int. J. Androl. 21: 2-7. 